\title{
METAPHYSICS OF THE UNIVERSE IS A RENEWED INSPIRATION STRATEGY FOR ARTISTIC CREATIVITY WITH SUSTAINABLE THOUGHT
}

Yasser BADAWY *

Department of Interior Design, Faculty of Applied Arts, Helwan University, Egypt

\begin{abstract}
Metaphysics is a universal science and philosophy that calls for philosophical and contemplative thinking and the realization of reason within the scope of "the objects of things and the being", the creative link of most modern theories in art, design and architecture, related to the inspiration of the universe and nature, However, the philosophy of metaphysics did not take enough attention from the researchers of artists and designers to put it into real application and to benefit from its principles in artistic expression, And the creation of artistic concepts that affect the prevailing artistic traditions and habits. The research was revealed as a strategic vision applicable to applied and applied arts, architecture, interior design, literature, poetry, music, visual arts, animation, audio and speech arts and media arts.

Keywords

Metaphysics, The Universe, Strategy, Artistic, Creativity, Sustainable Thought.
\end{abstract}

\section{Introduction}

The research sought to find solutions to the research problem that was manifested in the absence of the concept of the relationship between metaphysics as a philosophical calligraphy rooted in existence, the universe and nature, and its separation from the global vision of artistic creativity, which is the production of designers, artists, musicians, architects, writers and poets The research answered many questions such as how to get inspired by the metaphysics of the universe in many visions and creative solutions in a more liberal style and thought, and how the inspiration comes renewed and parallel to all generations and ages and the strategy followed by the artist to achieve the system of creativity and the Art production is original and renewed, The solution is to apply the philosophical principles of Metaphysics to the entire artistic production of "fine arts, literary, design, engineering, musical." This in turn leads to the creation of a strategic system that produces artistic creativity characterized by qualities of originality, innovation and sustainability, and produces creative generations of creators.

Artistic inspiration through the application of the principles of metaphysics to artistic production means achieving the most important principles of the universe, the principle of movement, thus obtaining a sustainable artistic production characterized by the characteristics of life, fulfilling the functions and needs of humanity, and conforming "artistically, 
environmentally, functionally and creatively" to the environment. And through the material embodiment of the elements of inspiration derived from the metaphysical forces inherent in the cosmic nature in the reality of tangible art embodied the intellectual nature of the designer and artist materially after the interaction of his Subjective with those forces in the "natural or artistic subject, The result of this interaction is a work of art of a technical nature, prepared by the characteristics of life, which gives it spiritual and aesthetic values that reveal the secrets behind the transient form of contents and visions and reach a sustainable creative vision that conforms to the principles of the universe after its abstraction, from formation to abstraction , Thus achieving the objective of research in reaching a vision of creativity with sustainable characteristics. Leading to a theoretical framework represented by cognitive models of natural sources of inspiration and analysis of results with final conclusions and recommendations.

\section{Research problem:}

Philosophy seemed to be dominated by abstract theories and far removed from the world of experience and the reality of life, and now it lacks practical application and the act of creative and artistic practice in society. This is a result of the absence of the concept of the relationship between metaphysics as a philosophical trend striking its roots in existence, the universe and nature and the inspiration of its essence and its sustainable principles and its separation from the global vision of artistic creativity represented in the production of designers, plastic artists, musicians, architects, writers and poets, which led to the lack of the sustainable metaphysical dimension that gives the soul to artistic production. Arts are forms without connotations, visions without meaning, and artistic subjects that lack objectivity, lack sense, intuition, and creative human vision, so they are separated from their content, content and essence, and isolated from our innocent humanity and from its spatial, temporal, environmental and sustainable cultural environment. Research questions: All artists, including designers, plasticists, architects, poets, writers, and musicians by nature form within them a state of nostalgia and adoration for nature, the universe and existence, the inspiration for their works and artistic creations, even those who deliberately refrain from resorting to nature and its displacement from its pervasive and rooted in its being and self-intuition for creativity, although the production of the art It comes naturally that is not without the influence and spontaneity of nature, so these same questions were imposed: Does the artist always reveal and reveal to us the sources of his inspiration?, And what is the contemporary way of looking at the universe through which we can draw inspiration from many creative visions and solutions in a more liberal style and thought in keeping with concepts Societies ?, and how does inspiration come renewed and accompanying all generations and eras ?, Is there a strategy with 
specific parameters, clear procedures and a path that the artist can follow in order to achieve the creativity system and the artistic production to be genuine, original and renewable ?, Is there an acknowledgment that modern and contemporary theories of creativity in interior design and architecture And the arts follow a metaphysical approach to the inspiration of laws and theories of creativity, which the artist follows in order to achieve the creativity system and be The artistic product is real, original and renewable production? Is there a recognition that modern and contemporary theories of creativity in interior design, architecture and the arts take a metaphysical approach in inspiring laws and theories of creativity from the universe, existence and nature without recognition of metaphysics with this merit? To philosophers and aesthetics, it is basically a school of divine and Quranic inspiration and a faith call to contemplate the signs of God in the universe? And finally, is philosophy metaphysics the ability to answer these questions?

\section{Meanings and terms related to the creative artist:}

artistic creativity, artistic imagination, artistic inspiration, sustainable artistic creativity. Existence: The word Existence is derived from the Latin word Existere, which means getting out of something in the sense of leaving the state in which the thing exists to place itself where it was not before, survival, permanence, existence: everything that exists or can exist, constitutes a thing Reality, which is of two types: mental and external, as opposed to nothing. Ontology: (Philosophy and Mysticism) is a branch of metaphysics that researches the nature of existence. Existence is a moving substance in a "place" space, place is a primary presentation defined by matter, and time is a secondary presentation, which is the analogy of space by motion. As if existence is based on three elements: matter, motion, "time", and space. These elements are all different in nature, and their differences predispose the organization and diversification of the structure, many identical atoms that build one simple universe that does not distinguish between its parts, but the occurrence of the movement of atoms in space leads to the diversification of cosmic structures. The universe, in its many different forms, is a component of this trinity: matter, motion and space. We see a similarity in the images and forms of the universe, then we see a connection between its parts and groups. So this vision establishes in our minds another moral existence according to which the images and forms of the universe are formulated - it is the geometry of the universe.

- Universe: In the dictionary of meanings, the universe: the absolute and general existence, and the adding of the universe: a science that researches the appearance of the universe and its general structure, the science of the universe: a science in which it searches for the world in terms of its natural laws by which it proceeds. The meaning 
of being in the dictionary of Al-Waseet dictionary, God being a thing: He brought it out of the uncle into existence, created it, created it, created it and was: - God is the world / creation. The Supreme Universe: God.

- Nature: in the Collective Dictionary of Meanings (Nature) Name: Creation and Genie upon which man is mounted, Fitrah, Nature: the force in the bodies through which the body reaches its natural perfection, the world of beings, (Nature Science): a science that searches for the natures of things and what I specialize in it, the science (of nature and physics) is physics, a science that searches for the natures of matter and its images.

- Cosmic Creativity (cosmic beauty - cosmic majesty ...): the word creativity in the Arabic language is a word rich in meanings related to the meaning of creation, related to the word in its English origin, which means creativity, and the word creativity circulates in the dictionaries of the Arabic language as well as in the medieval dictionary. The tongue of the Arabs has several meanings. They converge in: Creating a thing is based on a previous example, and making it an end in its characteristics.

- Creativity: (among the philosophers): finding something out of nothing, it is more specific than creation. God created the universe: He created it, created it from nothingness, and among the meanings of innovation and innovation in the tongue of the Arabs is the thing that comes first and it is said about the creator of the thing: It is her creator is a heresy, and he invented it : Ie invented it, the example and the end in everything. The Almighty said: (The Most Beautiful of the Heavens and the Earth), for $\mathrm{He}$ is the Creator and Creator of it in the ultimate in purity, beauty and creativity. Beauty: An attribute that notices things and brings pleasure or a sense of orderliness and harmony in the souls, and it is one of the three concepts to which the judgments of values are attributed: beauty, truth, and goodness. God is beautiful and loves beauty (noble hadith.(

- Majesty: the concealment of truth in the veil of glory from knowing the truth of his sacred self, so that he does not see himself and does not know it except God, the Most Exalted, the Majesty of God: His greatness, the Sublime, the greatness and the absolute dispensation, Surah: The Most Merciful, Verse No. 78, Majesty God: His majesty, and only God is said to be glory. The Sublime: One of the attributes of God is sanctified and exalted, and the great matter may be described by it.

- Sustainability of the universe: sustainability according to the dictionary of meanings, sustainability: (name) a source of sustainability, permanence, continuity, sustainability: 
continuity, immutability and eternity, the miraculous creation (the universe - man matter - atom) is designed as a creature, the Almighty says: And except for everything Created by the power of [the moon: 49], that is: a capacity of power, and the creatures have guided to him and everything that God created in the universe was created with specific quantities and specific qualities that ensure the ability to provide adequate means of life for man and other living creatures that have life on earth.

- Artistic creativity: creative thinking: an original creation, the power of creativity: the power of innovation and throat, innovation, finding something unprecedented by a substance or time, it brought about innovation, created something: extracted, took it, (culture and arts) was creative, a literary and artistic tendency that highlights the imagination Creativity, self-expression and exaggeration of nature and its beauty, characterized by the development of new methods, a return to nature and the preference for Hussein and passion for reason and logic (unlike classical adherence). It is also known as romanticism, romanticism or romanticism. Creativity is, in fact, due to a conscious process, as a product of a process between the subject and its object. And an initiative shown by the artist, which is his ability to get rid of the normal context of thinking, and to follow a new pattern such as adventurous thinking that is characterized by leaving the previously decreed path and getting rid of the formulated templates, and embracing the experience, and allowing something to lead to others. From the foregoing, artistic creativity can be defined as the ability to imagine, invent, or create new artistic installations or organizations by synthesizing ideas, modifying or changing them, and it is also the ability to produce original ideas and unique solutions using imaginations and perceptions, and give meanings to ideas.

- Artistic Imagination: In the dictionary of the medieval dictionary, imagination: what you see as a shadow, which is: one of the powers of the mind through which things are abandoned, and imagination is the spectrum, "imagination is more important than knowledge, it is a preconceived vision of gravity and future life" - Albert Einstein and imagination is the queen of the creator and the beginning towards Creativity, and it has its dynamic role as a mediator between sensation and thought, between sensory perception and mental perception, as a queen and energy, or it is a perceptive psychological force of sensory images or tangible things with my mind evoking its unseen, and artistic imagination is the basis for all creativity as it evokes or evokes beauty from all forms of the universe, It is considered a psychological activity during 
which the processes of synthesis and merging between the components of memory and perception and the mental images that were previously formed through past experiences and the results of all of this are new mental formations, and the imagination process is one of the basic processes that the artist uses in his pursuit of unfamiliar ideas, perceptions and experiences, One of its types is fictional or creative imagination, a type of creative inspiration in which a person uses all his senses in order to produce many creative ideas.

- Inspiration: Inspiration: A source of inspiration, in the Collector's Dictionary of Meanings, Inspiration: the rhythm of something in the heart that comfortably rests in the chest, with which God has some of its purists. That God casts a person's soul into something that prompts him to do or leave something. What meanings and thoughts thrown into the heart or mind. Inspiration, a source of inspiration, inspired, a servant of those who have the ability to generate meanings and ideas from poetry, drawing, music, etc., and an elegant ability to evoke ideas and meanings during writing, design, photography or sculpture, which is a guide from his inspiration.

- Sustainable artistic creativity: according to the definition of the Wikipedia Encyclopedia: Sustainability Sustainability for humans is the ability to preserve the quality of life that we live in the long term, and this in turn makes the earth capable of supporting human life as we know it. And sustainable artistic creativity can be defined as creativity linked to the morals and values of man. It provides the concepts of sustainability as an ethical dimension and mandates all human beings to respect nature, the systems of the universe, values, beauty and all forms of life to create a sustainable civilization in which riches are integrated on earth, and it is creativity that fulfills its purposes in its nation and in humanity, when it is common. In it the pigment that dyed his belief and characterized his ideology, is the creativity of man: artist, designer, architect, poet, writer, composer, music, a human creativity in the first place characterized by beauty, and always aims at sublime art through a sensory material that embodies beauty and connects it to a sense The viewer or the listener (the recipient), the job to the user, and the safe and comfortable space environment for the coexist, which is his elevation towards the supreme, the highest and the most beautiful, as it is a tendency towards transcendence in feelings and a refusal to fall. Introduction Introduction to the research topic: The creative vision of research is a promising vision proposed to give a modern characteristic to the outcome Artistic creativity in light of a 
philosophy that draws inspiration from the metaphysics of the universe, and research combines a set of philosophical concepts of metaphysics science and the extent of its relevance to the universe and put it as a strategic vision Promising, in an attempt to clarify concepts absent from many researchers, artists and designers, so that they have an original and renewed source of artistic inspiration, so the vision of the research aspires to be applicable to plastic and applied arts, architecture, interior design, literature, poetry, music, and all visual, kinetic and audio arts. This vision is based on a cosmic philosophy that claims that the universe and its assets speak with its oneness God Almighty, addressing the minds and hearts and calling for reflection, and the universe is the unity of its appearance, the integration of its parts that have been arranged with great precision is reflected in a building unit "in the phenomena of a single cosmic structure." Therefore, production Contemporary art is claimed to be dominated by unity of construction and purpose as arts directed to address the human mind, sentiment, feelings, eyesight and hearing in the first place.

Although every art has its tools, materials, means of inspiration and principles, all arts share in the unity of artistic construction, all of them | The production of beauty achieved in the works of the artist who is conscious or "feeling". The closer it is to its honorable goal, the more it should be considered a true artistic creation. Its function is inspired by the fulfillment of its purposes, the expression of what matters to the human being regarding his religion and world, and the service of truth, virtue and justice, and for the sake of goodness and beauty. Audio arts such as: music, singing, muwashahat chanting, and recitation arts. And visual arts such as: architecture, interior design, sculpture, photography, engraving, mosaic, drawing, cartoons, miniatures, and calligraphy. And all applied arts and design arts such as: (glass ceramics - sculpture ornaments, jewelry decoration - fashion printing - advertising ....). And arts (audiovisual) such as: animation, theater, cinema, acting, music, singing and chanting, dance, ballet, and performing arts. And the arts of the word, such as: the chant, the poem, the story, the prose, the novel, the poetry, the good word, and rhetoric. And media arts such as: video art, electronic arts, and internet arts.

All cultural and philosophical visions confirm that the most important objectives of artistic creativity are: the development of emotion and conscience, the development of the skills of the senses and their training in mastery and mastery, motivation of the 
human being to creativity, innovation and self-affirmation, controlling emotions and taming unruly tendencies and putting them in a state of equilibrium, appreciation of manual work and design and manufacturing skills Opening the space for imagination and investing it in the service of mankind and urbanism, and in light of the orientation of scientists and artists in all their artistic, design and engineering fields of nature, the universe and existence and returning to their principles, and discovering those superior capabilities and creative potentials that still contribute to the innovation of modern technologies in all sciences and arts, as it has become in focus Scientists' interest in understanding nature, using it in useful applications, and new innovations inspired by the understanding of the universe system and nature and the concepts behind it that made it sustainable in its system and in its form, so the research was directed towards the science and philosophy of metaphysics as an innovative philosophy in the first place that did not take its share by researchers from artists and designers To bring it into real application and benefit from its principles. Metaphysics in research is a call of faith and a call for philosophical and contemplative reflection on existence and beings, and the realization of the mind within the scope of "the essences of things and being", in order to search for true knowledge and the essence and essence of things. This is evident in the address to God Almighty to all minds at all times and urging them to reflect, delve into and contemplate His Almighty kingdom, even though the term metaphysics was only known in the first century B.C., and here in the folds of this research we re-shed light on the philosophy of metaphysical inspiration to present an invitation to all artists Designers for reflection, contemplation, contemplation and research, aiming to present artistic and design production as an integrated artistic state governed by the principles of sustainability, which is dominated by thought in addition to its interest in the recipient's direct artistic aspects related to the sense and the physical view. Perhaps the main function of art is to cultivate the human soul and raise it to the highest ranks of aesthetic expression. The transcendence of society, its entertainment, persuasion and service, as part of the culture of any nation, left its mark on the societal culture and creativity Concepts and beliefs that affect prevailing customs and norms.

\section{research results:}

1- If we take from an artistically placed plant leaf for metaphysical inspiration, the shape and structure of the plant structure tells us the mechanism and mechanism of the structure that prepares the plant leaf to carry out the process of food manufacturing, photosynthesis, respiration, transpiration and excretion, it is these forces that allow light 
to penetrate the entire tissue and give it the ability to store food and water, And the forces that change in shape and characteristics to achieve purposes and functions appropriate to the surrounding environment in order to carry out certain functions, this creative system hidden behind the apparent form presents us with a renewed inspiration strategy, but rather provides humanity with a sustainable means that makes the air suitable for breathing, as it releases oxygen during the photosynthesis process, Without the processes performed by the leaves, the amounts of oxygen available to breathe on the surface of the earth will run out in a short time, as the leaf is a sustainable cosmic element and it is believed that the age of the leaves goes back to 400 million years.

2- Art in metaphysics is a deepening of the world of rich experience, which is listening to the heartbeat of reality, metaphysics as a contemporary inspiration philosophy that acquires artistic creativity in its entirety the characteristic of the artistic state in harmony with the universe, and its conscious applications divide us with strategy for them our creations with models inspired by nature and the universe (within the trends of contemporary artistic creativity) An investigator who merges the principles of metaphysics with contemporary design theories and sciences whose metaphysical basis is the universe and metaphysics.

3- Real artistic creativity is the one that achieves its purposes in his nation and in humanity, when the color that has been dyed by his belief and characterized by his ideology is common in it, the creativity of man .. the artist, designer, architect, poet, writer, composer, music, they are invisible metaphysical strings that are those that The divine status is linked to the beautiful human creativity, the goal that the sublime art aims to achieve is to convey beauty to the sense of the viewer or the listener (the recipient), the function to the user, and the safe and comfortable space environment for the coexist, which is to elevate him towards the supreme, the highest and the most beautiful. In sentiment he refused to fall.

4- The product of true artistic creativity under the philosophy of metaphysical inspiration acquires its sensory and metaphysical qualities when it is the product of a mental process that depends on a set of capabilities characterized by characteristics that constitute a new addition to human knowledge in the field of art, so that this production becomes a sustainable necessity from the necessities of life and a constant aspiration for the forward and potential energy in The interior of the creative artist, an artistic experience that provides masterpieces influencing human existence, and one of the processes that lead to the development of products that are modern and serious based 
on standards and principles established by man based on the values and principles of the universe, nature and existence.

5- The global environmental and ecological crisis, the crisis of the decline of culture, the declining level of the arts, ... crises related to the morals and values of mankind, and human actions are responsible for these crises, and the concepts of sustainability provide an ethical exception and authorization for all human beings to respect nature, the universe's systems, values, beauty and all forms of life to create A sustainable civilization To benefit from the fate of past civilizations, to reflect on them and to celebrate the symphony of a life in which the arts on earth are integrated, all human beings need to promote and protect biological, cultural and artistic diversity, and religion can become a strong part of the solution if people embody a holistic spiritual vision towards humanity, the earth and the universe.

6- Artistic creativity that expresses the characteristics of sustainable thought is a creative human product, a color from human culture, which expresses subjectivity and identity, and it is a creative product of a person who expresses his thought, translates his feelings, carrying the connotations of sentiment, feeling, feeling and imprint of the human soul, and an attempt to embody the true essence and content From the metaphysical rhythm that he receives in his life from the realities of existence, or from his perception of the realities of existence in a beautiful and moving image that remains a positive impact on humanity.

7- Relying on the thought of metaphysics and its constructivist philosophy that deals with the metaphor of the "principle" or "the logic of form" in the natural subject, which is dominated by the characteristics of life more than just the quotation of the outward form, and its reflection on the work of art, and the various systems it achieves more stable leading to Sustainability.

8- The perceptual recording of the metaphysical forces inherent in the universe, represented by a spatial or architectural structure, a sculptural or design work, or a piece of music is an amalgamation of the aesthetic, environmental, urban, ethical, cultural, social and political values, through an incomplete metaphysical reflection of the realm of the sensible in the realm of the sensible, through an abstract sensory material It is governed by a certain scale, a certain compliment, a certain scale, or a certain rhythm that is controlled by the artist's subjectivity and his deep sense of beauty. It is the spontaneity of matter and its chaos looking for a metaphysical rhythm of life.

\section{Research recommendations:}


1- The keenness of the state's leadership, government and institutions to introduce creative concepts in government institutions, to introduce prizes and sponsors of creativity, and to create institutional culture environments that emphasize in its strategy the importance of commitment to creativity as a supreme institutional value.

2- We call to support new cultural, artistic and design concepts that emphasize and link faith, beauty, reason and compassion to ensure a sustainable artistic strategy with insight, and we also call for rethinking educational systems that neglected the beauty of nature and the universe.

3- Artistic freedom and creativity are key to sustainable development. Cultural policies that guarantee freedom of expression and encourage creativity are essential for the country's long-term development. Creating a strong correlation between the concepts of functional creativity and institutional creativity, so the more this correlation, or rather cohesion, united, interdependent and mutually exclusive, the more the concept of creativity between them is more mature, productive and profitable.

4- The pursuit of creative organizations on an educated thought based on strategies that define the place and the horizon at the same time, and cooperation in the work environment will lead to the cross-fertilization of unilateral thought with collective thought to create an exceptional creative thought that has a creative character.

5- Creative empowerment is an important requirement and exceptional motivation. Modern technical thinking is based on facilitation in everything.

6- Let us fly in the sky, art and unlimited generosity, mixed with love, passion and passion. To discover the secrets of art, in its essence, does not constitute it, to reach a literary, visual, musical, design, architectural message ...... Creativity is unique and here lies the transcendence of great and sustainable ideas.

7- Increasing diversified sources of funding to support creative biology research, more applied fields, and establishing applied arts and engineering research centers to help link basic research and the growth of applications in the industry. Experimenting with general concepts of how form and function relate to the environment.

8- Philosophy must descend into reality and go into the midst of lived experiences, bear the trouble of responsibility, create the most appropriate solutions to problems, understand situations, take into account the idiosyncrasies, and stop at the details and inhabit the fields of facts. Industrial, architecture and spatial environments of interior design into a cosmetic path of existence. 
The research recommends intensifying studies based on the creative relationship between metaphysics thought and philosophy and between modern and contemporary science and theories in art, architecture and design, and introducing them into the applied scope such as: Bio Inspiration - Biomimicry - Biometric Simulation Abstraction - Biogeometry Science Morphology - Energy Sciences - Morphology and Environmental Designing - Ecological science - Environmental architecture and its spatial structure - Green architecture and its spatial structure - Sustainable architecture and its spatial structure architecture and its spatial structure - biomorphic architecture cosmological architecture - universal music - border design - parametric design - kineti c design.

\section{References}

1- Imam Abd al-Fattah Imam; An Introduction to Metaphysics, Nahdet Misr for Printing, Publishing and Distribution, Cairo, 2005.

2- Boutros Al-Bustani; Al-Waseet Dictionary, The Arabic Language Academy in Cairo, Third Edition, Cairo, 1998.

3- Paul Ricoeur; The theory of interpretation, discourse and the excess of meaning, translated by Saeed Al-Ghanimi, Arab Cultural Center, Second Edition 2006.

4- Peter Coles; Cosmology - A Very Short Introduction, translated by Muhammad Fathy Khidr, publisher, Hendawi Foundation for Education and Culture, United Kingdom, first edition 2015.

5- Hassan Ahmad Issa; The Psychology of Creativity between Theory and Practice, Dar Al Fikr Publishers and Distributors, 2009.

6- Adel Mostafy; The significance of the shape: a study of aesthetics and a reading in the book of art, CIC Hindawi Foundation, UK, 2017.

7- Abbas Mahmoud Al-Akkad; Thinking is an Islamic Imperative, the publisher Hindawi Foundation for Education and Culture, United Kingdom, 2013.

8- Qasim Hussein Saleh; Creativity in Art, Studies Series (276), published by Dar AlRasheed Publishing, Iraq, 1981.

9- Clive Bell; Art, translated by Adel Mostafa, reviewed and presented by Michel Matthias, publisher, Hindawi CIC Foundation, UK, 2017.

10- Michael Denton; The Fate of Nature - Laws of Life Reveal the Existence of Purpose in the Universe, translated by Dr. Musa Idris - Dr. Muhammad Al-Qadi - Dr. Muhannad alToumi and others provide d. Muhammad Al-Awadi, Barheen Center for Research and Studies Edition, 1st January 2016. 
11- Mohamed Al-Jazaery; Creativity speech, the moving aesthetic essence, published by the Cultural Affairs House, Baghdad, 1993.

12- Muhammad Emara; The Book of Islam and Fine Arts, Dar Al-Shorouk, Cairo, 1991.

13- Preacher Sheikh Muhammad Metwally Al-Shaarawi The Cosmic Verses and Their

Evidence for the Existence of God Almighty, the Al-Islami website

http://www.Islammi.8m.com

14- Munir Abdullah Al-Hafiz. Ishraqat fi Philosophy of Art and Beauty, Dar Al Khaleej, First Edition, 2019.

15- Nicolas Haddad; The Philosophy of Existence, publisher Hendawi Foundation for Education and Culture, United Kingdom, 2014.

16- Youssef Karam; Mind and Being, Hindawi Foundation for Education and Culture, United Kingdom, 2014.

17- Edwards, Brian \& Chrisna du Plessis (2001), Snakes in Utopia: a Brief History of Sustainability, Green Architecture: Architectural Design, (AD), Vol. 71, No. 4, July 2001, Wiley - Academy, UK.

18- William Henry Walsh, A.C. Grayling, Bruce Withington Wilshire, "Metaphysics" britannica, Retrieved 16-4-2018. Edited

19- http://u092058.blogspot.com/2012/03/blog-post_770.htm19

20- http://www.diwanalarab.com/spip.php?article39489

21- http://www.diwanalarab.com/spip.php?article34458\#.XH_428AzaM92122-

22- https://mugtama.com/theme-showcase/item/80980-2019-01-05-08-18-06.html

23- https://mugtama.com/theme-showcase/item/80980-2019-01-05-08-18-06.html2324

24- https://en.wikibooks.org/wiki/Introduction_to_Philosophy/What_is_Metaphysics

25- https://vb.3dlat.com/showthread.php?t=1918262526

26- http://www.jameataleman.org/main/articles.aspx?article_no=117

27- https://www.ida2at.com/biomimicry-natureschool27

28- https://asknature.org

29- https://biomimicry.net29https://mugtama.com/theme-showcase/item/80980-2019-01-05-

08-18-06.html30

30- https://www.ida2at.com/biomimicry-nature-school3132-

31- http://iswy.co/evf1f

1- We are all created by measure. Dr.. Ahmed Awad Abdel-Hadi, Professor at the Faculty of Science, Minia University, published article, Encyclopedia of Miracles, Egypt. 2010/10/10 Scientific in the Qur'an and Sunnah, date of publication 
.http://www.quran-m.com/quran/articlesearch/3710.html

2- The science of simulation of nature and its various applications; Bassam Meristani, published article, http://www.arsco.org/article-detail-704-11-0, publication date, 7/13/2017 3.Metaphysics as metaphysics - connotation and meaning; Sufyan Baqash, published article, publication date 7/12/2017. https://www.mominoun.com

4- Ghazi Abbas Al-Abadi, a scientific research published, Al-Akademi Journal, 36. The theory of inspiration from nature in industrial design; The banks of the University of Baghdad, 2014.

5- The Sunnah of God in the horizons and in the souls is a definite indication of monotheism. Dr.. Nasir Ahmad Muhammad Sunna, published article, Encyclopedia of Scientific Miracles in the Qur'an and Sunnah, publication date 6/18/2010, Egypt. Http://www.quranm.com/quran/articlesearch/3710.html

6- Yasser Sayed Al-Badawi Abd al-Latif; A scientific research published entitled: Inspiration of the Movement in the Growth Forces of Natural Formation as the Principle of a Growing Spatial Architecture, (International Design Journal - Specialized Design Journal), October 2015.

7- Eman Mohamed Wagdy EZZAT, EXPERIMENTAL PRACTICES TO DEVELOP FORMAL AND FORMATIVE PRINCIPLES FOR HANDICRAFTS, International Journal of Multidisciplinary Studies in Art and Technology, Vol. 1, No. 2, 2018, pp. 10-41. 8- Salah Shaaban Hassanin ABDEL RAHMAN, FORGING BY HAMMERING ON COPPER BETWEEN CRAFTSMANSHIP AND CREATIVITY, International Journal of Multidisciplinary Studies in Art and Technology, Vol. 1, No. 2, 2018, pp. 42-46.

Received: February 4, 2019

Accepted: April 11, 2019 